\title{
Advancing the newborn and stillbirth global agenda: priorities for the next decade
}

\author{
Gary L Darmstadt, ${ }^{1}$ Jeremy Shiffman, ${ }^{2}$ Joy E Lawn ${ }^{3}$
}

${ }^{1}$ Global Development Division, Bill and Melinda Gates Foundation, Seattle, Washington, USA

${ }^{2}$ American University, Washington, DC, USA ${ }^{3} \mathrm{MARCH}$ Centre, London School of Hygiene \& Tropical Medicine, London, UK

\section{Correspondence to}

Dr Gary L Darmstadt, Global Development Division, Bill and Melinda Gates Foundation, Seattle, WA 98102, USA;

gary.darmstadt@

gatesfoundation.org

Received 12 September 2014 Revised 29 October 2014 Accepted 30 October 2014
CrossMark

\author{
To cite: Darmstadt GL, \\ Shiffman J, Lawn JE. Arch \\ Dis Child 2015;100
}

(Suppl 1):s13-s18.

\section{ABSTRACT}

Remarkable advances have been made over the past decade in defining the burden of newborn mortality and morbidity and stillbirths, and in identifying interventions to address the major risk factors and causes of deaths. However, progress in saving newborn lives and preventing stillbirths in countries lags behind that for maternal mortality and for children aged 1-59 months. To accelerate progress, greater focus is needed on improving coverage, quality and equity of care at birth - particularly obstetric care during labour and childbirth, and care for small and sick newborns, which gives a triple return on investment, reducing maternal and newborn lives as well as stillbirths. Securing nationallevel political priority for newborn health and survival and stillbirths, and implementation of the Every Newborn Action Plan are critical to accomplishing the unfinished global agenda for newborns and stillbirths beyond 2015.

\section{BACKGROUND}

Over the past decade, major progress has been made in outlining how to address newborn health and survival in low and middle income countries (LMICs). ${ }^{1}$ The burden of disease is clearly defined: newborn conditions comprise an estimated $8.1 \%$ of global disability-adjusted life years, approximately equivalent to that for cardiovascular diseases, exceeding the burden for all cancers combined, and threefold that for AIDS. ${ }^{2}{ }^{3}$ Research has identified effective interventions as well as bottlenecks and approaches to implementation of newborn health interventions at large scale. ${ }^{4-8}$

Despite a great deal of knowledge of what to do, newborn health remains poorly prioritised. Funding is inadequate for the burden; only $4 \%$ of donor funding allocations for child health for 75 LMICs mention the newborn. Moreover, partners lack convergence in their approaches to supporting country programmes, and data on coverage of interventions and use of data to improve programme performance are lacking. ${ }^{1}$ As a result, progress in reducing the annual 2.9 million neonatal deaths in the first 28 days after birth (2.0\% annual rate of reduction (ARR) in 1990-2012) lags substantially behind that for older children 1-59 months of age (3.6\%). ${ }^{9}{ }^{10}$ At present rates of decline, it will take over a century for African newborn babies to have the same survival probability as those born in Europe or North America in 2013. ${ }^{2}$

While commitment and actions to address neonatal survival are weak in many countries, stillbirths (defined by the WHO as born dead weighing $\geq 1000 \mathrm{~g}$ and/or after 28 completed weeks of gesta$\overline{t i o n}^{11}$ remain even more neglected. Interventions to prevent stillbirths are also known, and many have collateral benefits for maternal and newborn health, ${ }^{12}$ yet the ARR for stillbirths in highmortality countries was only $0.6 \%$ from 2000 to 2009. ${ }^{1}$ Moreover, a keyword search of official development assistance donor disbursement records for 2002-2010 identified only two mentions of stillbirth among 4584 grant or loan disbursements that included at least one newborn search term, ${ }^{13}{ }^{14}$ in stark disproportion to the 2.6 million stillbirths-including 1.2 million intrapartum deaths-that occur each year. ${ }^{11}$

Slow progress in neonatal mortality reduction (NMR) is a major factor preventing achievement of Millennium Development Goal (MDG)4 for child survival in many countries. Worldwide the proportion of under-five child deaths that occur in the neonatal period has risen from $36 \%$ in 2000 to $44 \%$ in 2012, and now exceeds 50\% in five developing regions. ${ }^{15}$ Preterm birth recently became the number one cause of death in children under the age of 5 years. ${ }^{16}$ Without greater attention to newborn health and survival, post-2015 targets for child survival and ending preventable child deaths cannot be met. ${ }^{2}$ Without concerted action to address stillbirths, more than one million women each year will continue to experience tragic loss and untold pain during childbirth. ${ }^{17}{ }^{18}$ To accelerate progress, three key elements must be further prioritised: (1) improve care at birth and for small and sick newborns, (2) improve equity for maternal and newborn care and (3) reach every woman and newborn and achieve impact at scale (figure 1).

\section{PRIORITIES FOR ADDRESSING THE UNFINISHED AGENDA}

Improve care at birth and care for small and sick newborns

Care at birth

One million newborns die on their birthday and 1.2 million babies succumb during labour and are stillborn; in addition, nearly half of maternal deaths (46\%) occur in the approximately $48 \mathrm{~h}$ period during labour, birth and the first day after childbirth. $^{2}$ The package of care with the maximum potential to avert newborn deaths and stillbirths is obstetric care during labour and childbirth (41\% and $70 \%$ of all newborn deaths and stillbirths averted, respectively). ${ }^{4}$ Care at birth is also most important for averting maternal deaths, and thus gives a triple return on investment (ie, maternal and newborn deaths and stillbirths averted) or quadruple if the consequences on child development from adverse birth events are also counted. ${ }^{4}$

Care for small and sick newborns

The second most impactful package of interventions is care for small and sick newborns $(30 \%$ of 


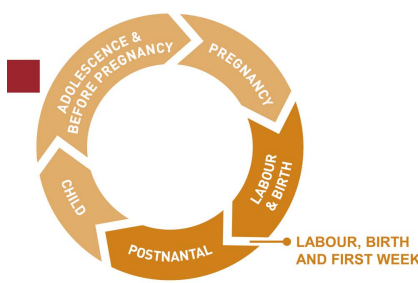

Securing and maintaining national-level political priority to accelerate progress in neonatal mortality reduction (NMR) enables countries to focus on improving coverage, quality and equity of care at birth and throughout the continuum.
ACCELERATING GLOBAL CHILD HEALTH PROGRESS:

THREE KEYS FOR NEWBORN SURVIVAL, HEALTH AND DEVELOPMENT

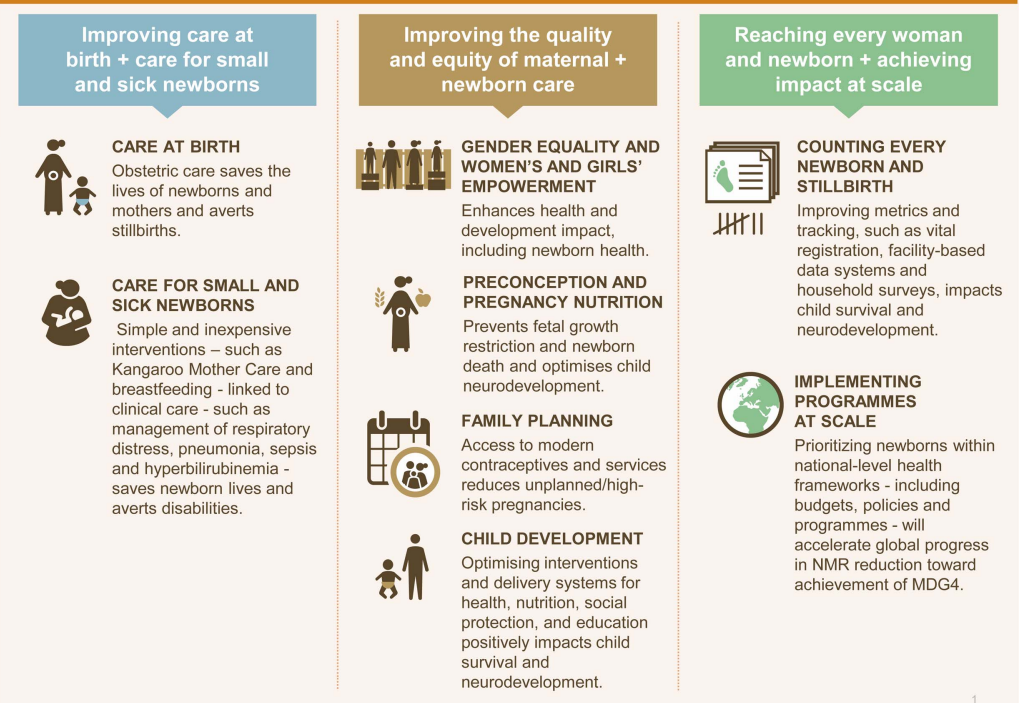

all newborn deaths averted), particularly during the first days to week after birth. ${ }^{4}$ Among the three leading causes of newborn deaths globally-complications of preterm birth, intrapartum conditions and infections-progress has been the least for addressing deaths due to preterm births $(<20 \%$ reduction from 2000 to 2012). ${ }^{2}$ In 2012, >80\% of neonatal deaths in sub-Saharan Africa and South Asia occurred in babies born too small, either prematurely $(65 \%)$ or small-for-gestational age (SGA, defined as $<10$ th centile of a standard optimal reference population for a given gestational age and sex) at term gestation (19\%). With available interventions-many of them relatively simple and inexpensive such as thermal care, resuscitation, Kangaroo Mother Care (KMC), breast feeding, antenatal corticosteroids, antibiotics for sepsis and pneumonia-an estimated $58 \%$ of newborn deaths due to prematurity could be averted by 2025 if high coverage (90\%) of care was achieved. ${ }^{4}$ Overall, care for babies born small and sick could avert an estimated 580000 newborn deaths per year; it should be noted that effectiveness of antenatal corticosteroids is based on data from middle-income and high-income countries. However, coverage for many of these interventions in LMICs remains exceedingly low-for example, just $11 \%$ for simple thermal care and $<10 \%$ for KMC and antenatal corticosteroids ${ }^{1}{ }^{4}$-and thus greater attention is needed to delivery of what we know works. In contrast, it is estimated that only a small fraction $(<5 \%)$ of preterm births could be prevented with existing maternal interventions (eg, progesterone supplementation, smoking cessation, cervical cerclage $)^{19}$; thus, greater investment is also needed in the discovery of new preventive interventions. An important step forward is the creation of a solution pathway to guide research investments to prevent preterm birth, ${ }^{20}$ as well as the rapid scale-up of effective interventions for care of infants born preterm, which will have a major impact even without intensive care. $^{21}$

Nearly three million lives of women, newborns and stillbirths could be saved each year through high coverage of care around the time of birth and care of small and sick newborns at an additional running cost of only $\$ 1.15$ per person in the 75 highburden LMICs. ${ }^{4}$ Arguably, increased focus here has the greatest potential for accelerating progress in the coming decade. Promoting this agenda is central to the Every Newborn Action Plan (ENAP) (box 1, figure 2). ${ }^{22}$ Care at birth is also the target for innovation through the Grand Challenge in Development: Saving Lives at Birth. ${ }^{23}$

\section{Improve the quality and equity of maternal and newborn care}

Poverty and inequality, punctuated by societal conflict and humanitarian emergencies, and poor quality of healthcare underlie much of the world's newborn mortality and morbidity and stillbirths. Quality improvement in maternal and newborn care provides substantial opportunity to improve the distribution, delivery and impact of interventions, and must now receive further emphasis in programmes. ${ }^{7}$ Improving availability and access to primary healthcare workers equipped with knowledge, competencies and essential commodities, and linked to quality care at health facilities, will be necessary for saving lives and optimising neurodevelopment. Improving gender equality and women's empowerment, early nutrition and ability to plan one's family are particularly important avenues for advancing newborn health and survival.

Gender equality and women's and girls' empowerment

Addressing gender inequalities and empowering women and girls is widely recognised as fundamental for achieving global health and development goals, including equality. ${ }^{24} 25$ Several approaches to empowering women and girls are associated with improved maternal and child health outcomes, for example, education, control over household and community resources, equitable decision-making authority and physical safety. ${ }^{26}$ Women's groups at sufficient saturation in the community (eg, $>30 \%$ of pregnant women in group) are cost-effective for improving maternal and newborn mortality. ${ }^{27}$ Smart investments in development seek to identify and address gender inequalities and empower women and girls (eg, promotion of decisionmaking power) alongside sector interventions (eg, supply chain logistic to reduce contraceptive stockouts). However, much remains to be learned about the mechanisms and pathways- 
What is Every Newborn?

Every Newborn is a movement of parent groups and over 60 partner organisations responding to increasing demand from countries to accelerate action on newborn survival and health, closely linked to maternal health. The Every Newborn Action Plan provides an evidence-based roadmap to reduce preventable newborn deaths and stillbirths, and to increase human capital through a healthy start in life. Women's health is closely linked and counting the impact on both makes the case for investment much stronger. The evidence gives clear principles for action, but for each country context-specific adaptation linked to country strategies and accountability mechanisms is critical.

\section{How has the Action Plan been developed?}

The plan content is based on The Lancet Every Newborn Series with the data and evidence shaped by the input of thousands of stakeholders including $>40$ national governments, as well as donors and foundations, civil society groups and the private sector, as well as healthcare professional organisations. The Every Newborn process is coordinated by UNICEF and the WHO in support of the UN Secretary-General's Every Woman Every Child platform to implement the Global Strategy for Women's and Children's Health. The plan was endorsed at the World Health Assembly 2014 by 194 member states with commitment to implement and track the process and results.

\section{What does the Action Plan include?}

Vision: A world with no preventable deaths of newborns or stillbirths, where every pregnancy is wanted, every birth celebrated, and mothers, babies and children thrive and reach their social and economic potential.

Goals for 2035, linked to the post-2015 development framework: For all countries to have a neonatal mortality rate $<10$ deaths per 1000 live births by 2035 , and a stillbirth rate $<10$ per total births by 2035 , with interim 5 -yearly targets to enable monitoring. ${ }^{2}$ These targets have been developed on the basis of extensive consultation and the full wording includes an explicit focus on equity and on child development outcomes. Analyses indicate that these targets can be reached by achieving universal coverage with existing interventions.

Guiding principles: Country leadership, human rights, integration, equity, accountability and innovation.

Actions: The Plan outlines the latest evidence on costs and expected impact of interventions, and calls for implementation by all stakeholder groups. An expected output in countries is an integrated reproductive, maternal, newborn and child health plan - not a separate newborn plan — which is sharpened to include the highest impact interventions for care at birth and care of small and sick newborns in that country context. This emphasis lies at the heart of universal health coverage, and a functional health system that works for the poorest, as well as wider coverage along the continuum of care-notably also for family planning services, pregnancy care and child healthcare.

The Plan has five strategic objectives to achieve the targets (figure 2).

1. Strengthen and invest in care during the critical period of labour, childbirth and the first days of life.

2. Improve quality of maternal and newborn care.

3. Reach every woman and every newborn and reduce inequities.

4. Harness the power of parents, families and communities for change.

5. Count every newborn: improve measurement, oversight and accountability, including birth and death certificates.

\section{How does Every Newborn build on other plans and efforts?}

Every Newborn builds deliberately on the targets, interventions, strategies and/or processes proposed by other efforts to promote women's and children's health. These efforts include Committing to Child Survival: A Promise Renewed, with its emphasis on eliminating preventable child deaths by 2035, and also the maternal mortality post-2015 targets, as well as Family Planning 2020. Every Newborn emphasises approaches consistent with the UN Commission on Lifesaving Commodities for Women's and Children's Health, which includes four life-saving commodities specific to newborn survival, the Scaling Up Nutrition framework for action, the Global Immunization and Vaccine Strategy, the Global Action Plan for the Prevention and Control of Pneumonia and Diarrhoea, and Countdown to Zero for eliminating Mother-to-Child Transmission of HIV and improving the health of women with HIV. Wider environmental change is also needed, notably for water, sanitation and hygiene. Plans are an important step towards action; however, their proliferation can also promote issue-specific tensions and pull national stakeholders into multiple meetings, even distracting from implementation.

The key message of Every Newborn is a call for context-specific attention to ensure newborns no longer fall between the gaps in the continuum of care and between multiple plans. Given the core value of a healthy start in life and the vulnerability of newborns, they deserve special attention within many issue-specific plans (adapted from ref ${ }^{8}$ ).

including their measurement-whereby addressing gender inequalities and promoting women's and girls' empowerment enhances health and development impact, including newborn health.

\section{Preconception and pregnancy nutrition}

In order to prevent deaths in small babies and optimise child development, greater attention is needed to nutritional care of adolescent girls and women in the preconception period and during pregnancy. An estimated 15 million babies are born preterm $^{28}$ and over a quarter (27\%) of all births (32 million) in LMICs are SGA, and rates are highest where maternal malnutrition and adolescent pregnancy are also the greatest. ${ }^{28}{ }^{29} \mathrm{~A}$ recent pooled analyses of 22 population-based cohort studies in LMICs underscored the magnitude of the adverse consequences of SGA (relative risk (RR) for neonatal mortality 1.83 compared with appropriate for gestational age (AGA) infants), particularly in combination with preterm birth (RR 15.42 compared with term AGA infants). ${ }^{30}$ Moreover, preterm and SGA babies are at increased risk of poor growth-20\% of postnatal stunting and 
Figure 2 Integrated packages of care for reproductive, maternal, newborn and child health showing the focus of the Every Newborn Action Plan on care around the time of birth.

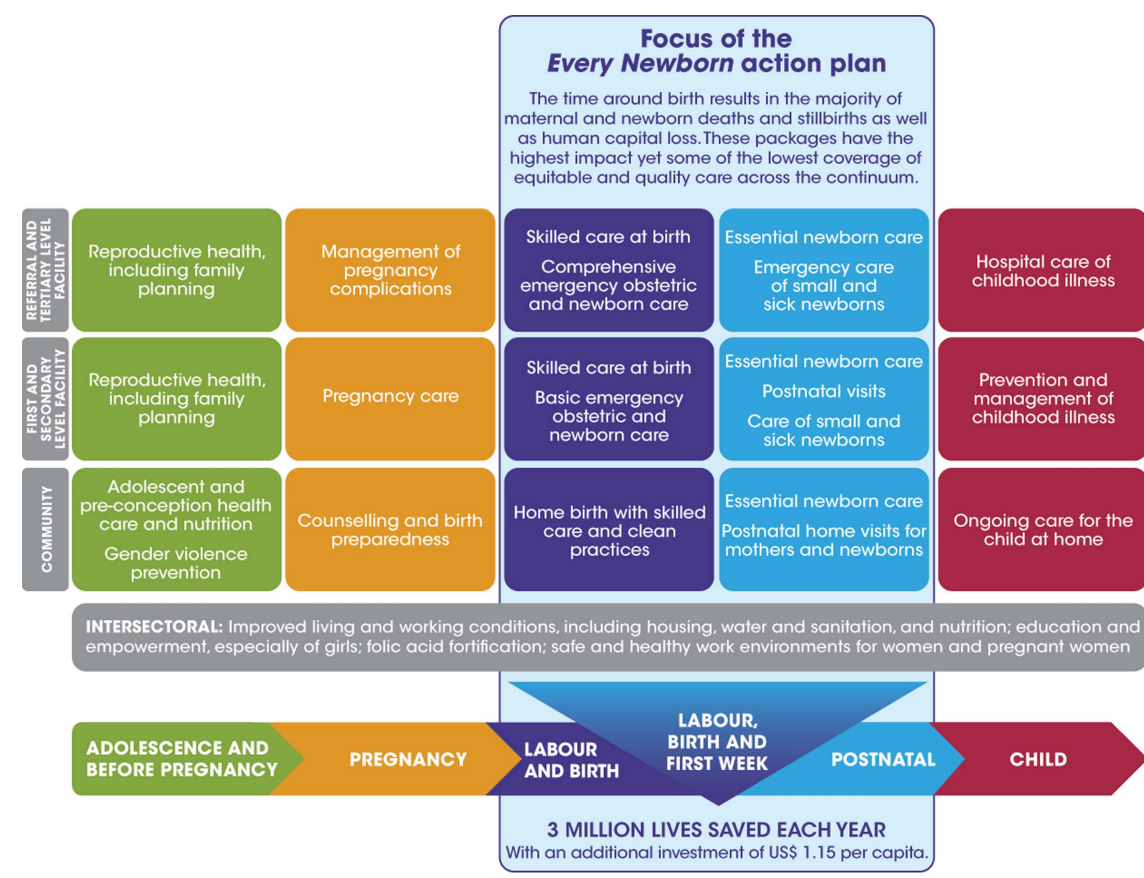

$30 \%$ of wasting are attributed to being born $\mathrm{SGA}^{29}$ - and adult-onset diabetes and cardiovascular diseases as well as neurocognitive impairment. ${ }^{2}$ Efforts to reduce SGA have focused primarily on increasing protein and calorie intake (which reduces SGA and stillbirth) and addressing micronutrient deficiencies (eg, multiple micronutrient supplementation, which reduces SGA) during pregnancy ${ }^{4}{ }^{31}$; however, extending intervention approaches to include adolescent and preconception nutrition (eg, folic acid supplementation) is urgently needed.

\section{Family planning}

Linkages between reproductive health and newborn health and survival have received increased attention in recent reports, ${ }^{2} 3233$ but need further analysis ${ }^{2}$ and emphasis in country programmes. Communities in LMICs with the highest fertility rates tend to also have the highest NMRs, ${ }^{2}$ and mortality is $40 \%$ higher for children born to young women and girls under the age of 18 years compared with children born to older women. ${ }^{32}$ Interpregnancy intervals shorter than 18 months and longer than 59 months are associated epidemiologically with increased risk of preterm birth and SGA. Moreover, if spacing between pregnancies was at least 2 years for all children, mortality among infants and children aged $1-4$ years would fall by an estimated $10 \%$ and $21 \%$, respectively.

An estimated 222 million women and girls-162 million of them in LMICs-who do not want to get pregnant lack access to contraceptives, information and services, and are defined as having unmet need for family planning. ${ }^{33}$ Addressing unmet need for family planning in LMICs with use of modern contraceptives would avert (based on estimates for the year 2012) 54 million unintended pregnancies, 26 million abortions, 79000 maternal deaths, 600000 neonatal deaths and 500000 postneonatal infant deaths annually. Family planning reduces unintended and high-risk pregnancies, and can delay age at first pregnancy and enable healthy timing - including delaying onset of childbearing-and spacing of births. ${ }^{32}$ Thus, family planning is a powerful approach for improving the health of women and their newborns and children. Moreover, recent analysis shows that the LMICs with the fastest reductions in NMR also had rapid reductions in total fertility rate, in some cases within a decade and in the absence of major advances in the economy or girls' education. ${ }^{2}$ This indicates that demographic transition can be accelerated and suggests that changes in family size are associated with higher newborn survival. Commitments to advance family planning in LMICs generated at the London Summit on Family Planning in 2012 and supported through Family Planning 2020 provide a key opportunity to advance newborn health and survival, as well as improve outcomes for women and integration of service delivery. 3435

\section{Child development}

As child mortality falls, attention turns increasingly to optimisation of child development and long-term economic productivity potential. The global burden of disabilities due to newborn conditions was recently quantified for the first time,${ }^{26-39}$ revealing that risk of disabilities is greatest in middle-income countries where survival is improving but establishment of neonatal intensive care and assurance of quality care is uneven. ${ }^{40}$ Most disabilities in these settings, however, occur in preterm infants $28-32$ weeks gestational age and are preventable with improvements in quality of care. ${ }^{2} 40$ High-income (low mortality) and low-income (high mortality) countries tend to have low risk of disabilities among survivors due to availability of quality care in the former settings and death rather than survival with disabilities for many newborns with severe morbidities in the latter settings.

Currently, interventions and programmes to address child survival and child development tend to be implemented separately, often through different ministries and partnerships. Several global initiatives are underway to validate measurements of child development; define effective interventions across relevant sectors, including health, nutrition, education, child protection and social protection; and identify delivery approaches to simultaneously achieve improved child survival and optimal neurodevelopment at large scale in countries. ${ }^{41}$

\section{Reach every woman and newborn and achieve impact at scale}

Although progress in saving newborn lives lags behind that for older children, some measure of success has been achieved in most countries. ${ }^{1}$ Between 2000 and 2012, NMR reduction 
exceeded $50 \%$ in 13 countries and was $25 \%-50 \%$ in 102 countries, including 17 in Africa. Countries with the highest NMRs, however, made the least progress in reducing neonatal mortality and stillbirths.

\section{Count every newborn and stillbirth}

Coverage data for many of the most simple and cost-effective interventions for averting newborn deaths and stillbirths (eg, antenatal corticosteroids for preterm labour, clean delivery practices, newborn resuscitation, prevention and management of hypothermia, KMC, case management of neonatal infections) and quality-of-care measures are lacking, crippling performance improvement and accountability efforts. ${ }^{1}$ At an even more fundamental level, over one-third of babies in South Asia and sub-Saharan Africa never receive a birth certificate, and death registration is even poorer; stillbirths are invisible in most countries. ${ }^{2}$ Without registration and awareness, fatalism and inaction are enabled as social norms. Improved vital registration, facilitybased perinatal data systems and household surveys including additional neonatal and stillbirth indicators, as well as improved metrics and tracking for neurodevelopmental impairment, are urgently needed.

\section{Implement programmes at scale}

Several conceptual frameworks and tools for scaling up healthcare to avert neonatal deaths and stillbirths have been developed to inform planning and implementation of programmes. ${ }^{5} 64243$ Common principles across these frameworks for achieving impact include (a) convene and work with local communities to analyse and understand the local social and cultural contextincluding community beliefs, practices, perceived needs and preferences-as well as local policies, health systems, partners and evidence for what works ${ }^{44}$; (b) participatory design of solutions, addressing bottlenecks ${ }^{7}$ and missed opportunities, and integrating interventions into local systems, programmes and networks across the continuum of reproductive, maternal and child health and nutrition; (c) monitor progress and use data to adapt and improve the process and coordination of implementation and programme performance; and (d) spread solutions via networks and primary healthcare delivery channels. In countries where substantial progress has been made-Bangladesh (2000-2012 NMR ARR 4.3\%), Malawi (4.3\%), Nepal (3.8\%) and Uganda (3.8\%)-key success factors in achieving impact in saving newborn lives at scale have included strong national leadership and convening of partners around newborn health; effective use of global and local evidence to design and implement policies and programmes; linking community and facility-based care; balancing demand (eg, behaviour change) and supply-side interventions (eg, commodities); and accountability for results. ${ }^{1}$

To accelerate global progress, countries where the burden of neonatal morbidity and mortality and stillbirths are highest must prioritise newborn health within their budgets, policies and programmes. ${ }^{45}$ Major emphasis needs to be placed on ensuring that all groups working in countries on women's and children's health and nutrition include the newborn within their programmes. Moreover, reach to the poorest and most marginalised groups must be ensured.

\section{Finishing the unfinished agenda}

To enable countries to take up these priorities for accelerating progress, national-level political priority for newborn health and survival and stillbirths must be secured and maintained. Priority for newborn survival among global organisations concerned with health has grown over the past five years, as evidenced by the endorsement of the WHO and UNICEF-led ENAP (box 1, figure 2). ${ }^{22}$ Also, the Bill and Melinda Gates Foundation provided nearly $\$ 500$ million in grants with major neonatal health components between 2009 and August 2014, ${ }^{46}$ and the United States Agency for International Development has allocated \$500 million for a 5-year period beginning in 2014 for its flagship programme on maternal and child health, with newborn health as a core priority. ${ }^{47}$

However, high-level national political priority for newborn survival remains confined to a handful of countries, ${ }^{6} 48$ and for stillbirths is nearly non-existent. This situation stands in marked contrast to the political priority and resources many national governments provide for other health problems, including HIV/AIDS. Prospects for growth in national-level policy attention for newborn survival and stillbirths will depend on several factors, including (a) the emergence of effective national-level political champions; (b) the formation of cohesive national-level policy communities that take leadership on these issues; (c) evidencebased consensus on the set of interventions and policy alternatives needed to make progress; (d) the generation and dissemination of credible data on levels of burden and intervention uptake; (e) global agreements such as the MDGs that place pressure on countries to act and, (f) availability of resources from international donors to augment funds that national governments are willing to provide. $^{49}$

In order to meet the NMR targets established in the ENAP, there are 29 countries that will have to at least double their current rate of progress for NMR reduction. The ENAP provides the best opportunity yet for accelerating progress and realising these ambitious but achievable goals (box 1, figure 2). The goals and principles outlined above (figure 1), which are fundamental to the ENAP, have been adopted within A Promise Renewed, a global call to action to end preventable deaths. ${ }^{50}$ Newborn health and survival is also prominent in the new Global Investment Framework for Women's and Children's Health. ${ }^{51}$ In the near term, as we look beyond the MDGs to the Sustainable Development Goals, a critical step will be to incorporate outcome targets for maternal, neonatal and under-five child mortality reduction, and to add stillbirths, which remain invisible on this agenda. ${ }^{52}$ With new targets in place, it is time to move forward with a common voice and focused actions (figure 1) to finish the unfinished agenda.

Contributors GD prepared the first draft of the paper. JS and JEL provided critical inputs, including review and approval of the entire paper.

\section{Competing interests None.}

Provenance and peer review Commissioned; externally peer reviewed.

\section{REFERENCES}

1 Darmstadt GL, Kinney MV, Chopra M, et al. Who has been caring for the baby? Lancet 2014;384:174-88.

2 Lawn JE, Blencowe $\mathrm{H}, \mathrm{Oza} \mathrm{S}$, et al. Progress, priorities, and potential beyond survival. Lancet 2014. Published Online First: May 20. http://dx.doi.org/10.1016/ S0140-6736(14)60496-7

3 Murray CJ, Vos T, Lozano R, et al. Disability-adjusted life years (DALYs) for 291 diseases and injuries in 21 regions, 1990-2010: a systematic analysis for the Global Burden of Disease Study 2010. Lancet 2012;380:2224-60.

4 Bhutta ZA, Das JK, Bahl R, et al. Can available interventions end preventable deaths in mothers, newborn babies, and stillbirths, and at what cost? Lancet 2014 Published Online May 20. http://dx.doi.org/10.1016/S0140-6736(14)60792-3

5 Darmstadt GL, Oot DA, Lawn JE. Newborn survival: changing the trajectory over the next decade. Health Policy Plan 2012;27(Suppl 3):iii1-5.

6 Moran AC, Kerber K, Pfitzer A, et al. Benchmarks to measure readiness to integrate and scale up newborn survival interventions. Health Policy Plan 2012;27(Suppl 3): iii29-39. 
7 Dickson KE, Simen-Kapeu A, Kinney MV, et al. Health-systems bottlenecks and strategies to accelerate scale-up in countries. Lancet 2014. Published Online May 20. http://dx.doi.org/10.1016/S0140-6736(14)60582-1

8 Mason E, McDougall L, Lawn JE, et al. From evidence to action to deliver a healthy start for the next generation. Lancet 2014. Published Online May 20. http://dx. doi. org/10.1016/S0140-6736(14)60750-9

9 UNICEF, WHO, The World Bank, United Nations. Levels and trends in child mortality: report 2013. New York, USA: UNICEF, 2013.

10 Lawn JE, Kinney MV, Black RE, et al. Newborn survival: a multi-country analysis of a decade of change. Health Policy Plan 2012;27(Suppl 3):iii6-28.

11 Cousens S, Blencowe H, Stanton C, et al. National, regional, and worldwide estimates of stillbirth rates in 2009 with trends since 1995: a systematic analysis. Lancet 2011;377:1319-30.

12 Bhutta ZA, Yakoob MY, Lawn JE, et al. Stillbirths: what difference can we make and at what cost? Lancet 2011;377:1523-38.

13 Pitt $\mathrm{C}$, Lawn JE, Ranganathan $\mathrm{M}$, et al. Donor funding for newborn survival: an analysis of donor-reported data, 2002-2010. PLoS Med 2012;9:e1001332.

14 Hsu J, Pitt C, Greco G, et al. Countdown to 2015: changes in official development assistance to maternal, newborn, and child health in 2009-10, and assessment of progress since 2003. Lancet 2012;380:1157-68.

15 UN Inter-agency Group for Child Mortality Estimation (IGME). Levels and trends in child mortality: report 2013. New York, NY: UNICEF, 2013.

16 Liu L, Oza S, Hogan D, et al. Global, regional, and national causes of child mortality in 2000-13, with projections to inform post-2015 priorities: an updated systematic analysis. Lancet 2014 Sep 30. pii: S0140-6736(14)61698-6. doi:10.1016/S0140-6736(14)61698-6.

17 Froen JF, Cacciatore J, McClure EM, et al. Stillbirths: why they matter. Lancet 2011:377:1353-66.

18 Haws RA, Mashasi I, Mrisho $M$, et al. "These are not good things for other people to know": how rural Tanzanian women's experiences of pregnancy loss and early neonatal death may impact survey data quality. Soc Sci Med 2010;71:1764-72.

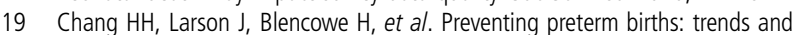
potential reductions with current interventions in 39 very high human development index countries. Lancet 2013;381:223-34.

20 Lackritz EM, Wilson CB, Guttmacher AE, et al. A solution pathway for preterm birth: accelerating a priority research agenda. Lancet Glob Health 2013;1:e328-30.

21 Lassi ZS, Kumar R, Mansoor T, et al. Essential interventions: implementation strategies and proposed packages of care. Repro Health 2014;11(Suppl 1):S5.

22 http:// www.everynewborn.org

23 http://savinglivesatbirth.net/

24 World Bank. World Development Report 2012: Gender Equality and Development. The World Bank, 2011. http://elibrary.worldbank.org/doi/book/10.1596/ 978-0-8213-8810-5

25 World Bank Group. Voice and Agency: Empowering women and girls for shared prosperity. 2014. http://www.worldbank.org/content/dam/Worldbank/document/ Gender/Voice and_agency_LOWRES.pdf

26 Gates M. Putting women and girls at the center of development. Science 2014:345:1273-5

27 Prost A, Colbourn T, Seward N, et al. Women's groups practising participatory learning and action to improve maternal and newborn health in low-resource settings: a systematic review and meta-analysis. Lancet 2013;381:1736-46.

28 Lee $\mathrm{AC}$, Katz J, Blencowe $\mathrm{H}$, et al. National and regional estimates of term and preterm babies born small for gestational age in 138 low-income and middle-income countries in 2010. Lancet Glob Health 2013;1:e26-36.
29 Black RE, Victora CG, Walker SP, et al. Maternal and child undernutrition and overweight in low-income and middle-income countries. Lancet 2013:382: 427-51.

30 Katz J, Lee $\mathrm{AC}$, Kozuki $\mathrm{N}$, et al. Mortality risk in preterm and small-for-gestational-age infants in low-income and middle-income countries: a pooled country analysis. Lancet 2013;382:417-25.

31 Bhutta ZA, Das JK, Rizvi A, et al. Evidence-based interventions for improvement of maternal and child nutrition: what can be done and at what cost? Lancet 2013:382:452-77.

32 Cleland J, Conde-Agudelo A, Peterson $\mathrm{H}$, et al. Contraception and health. Lancet 2012:380:149-56.

33 Singh S, Darroch JE. Adding It Up: Costs and Benefits of Contraceptive ServicesEstimates for 2012. New York: Guttmacher Institute and United Nations Population Fund (UNFPA), 2012. http://www.guttmacher.org/pubs/AlU-2012-estimates.pdf

34 Brown W, Druce N, Bunting J, et al. Developing the " 120 by 20 " goal for the global FP2020 initiative. Stud Fam Plann 2014;45:73-84.

35 http://www.familyplanning2020.org/?gclid=CjwKEAjwsdafBRC2rYuDuYXk2TESJACsUN_ uGpkxzgilzfrWDX2UA1gRBNJn-Kr34s8wfBosm3-LJhoC5YXw_wcB

36 Blencowe $\mathrm{H}$, Lee $\mathrm{AC}$, Cousens $\mathrm{S}$, et al. Preterm birth-associated neurodevelopmenta impairment estimates at regional and global levels for 2010. Pediatr Res 2013;74 (Suppl 1):17-34.

37 Lee AC, Kozuki N, Blencowe H, et al. Intrapartum-related neonatal encephalopathy incidence and impairment at regional and global levels for 2010 with trends from 1990. Pediatr Res 2013;74(Suppl 1):50-72.

38 Seale AC, Blencowe $H$, Zaidi $A$, et al. Neonatal severe bacterial infection impairment estimates in South Asia, sub-Saharan Africa, and Latin America for 2010. Pediatr Res 2013;74(Suppl 1):73-85.

39 Bhutani VK, Zipursky A, Blencowe $\mathrm{H}$, et al. Neonatal hyperbilirubinemia and Rhesus disease of the newborn: incidence and impairment estimates for 2010 at regional and global levels. Pediatr Res 2013;74(Suppl 1):86-100.

40 Lawn JE, Blencowe H, Darmstadt GL, et al. Beyond newborn survival: the world you are born into determines your risk of disability-free survival. Pediatr Res 2013;74(Suppl 1):1-3.

41 http://www.iom.edu/Activities/Children/InvestingYoungChildrenGlobally.aspx

42 Knippenberg R, Lawn JE, Darmstadt GL, et al. Systematic scaling up of neonatal care in countries. Lancet 2005:365:1087-98.

43 Bradley EH, Curry LA, Taylor LA, et al. A model for scale up of family health innovations in low-income and middle-income settings: a mixed methods study. BMJ Open 2012;2(4).

44 Bhutta ZA, Darmstadt GL. A role for science investments in advancing newborn health. Sci Trans/ Med 2014;6:253cm8.

45 Darmstadt GL, Munar W, Henry SK. Newborn health: Everybody's business. Global Public Health 2014:9:752-9.

46 http://www.gatesfoundation.org/How-We-Work/Quick-Links/Grants-Database

47 http://www.jhpiego.org/files/Jhpiego-Maternal-and-Child-Survival-Program\% 20Release.pdf

48 Smith S, Shiffman J, Kazembe A. Generating political priority for newborn survival in three low-income countries. Glob Public Health 2014;9:538-54.

49 Shiffman J, Sultana S. Generating political priority for neonatal mortality reduction in Bangladesh. Am J Public Health 2013;103:623-31.

50 http://www.apromiserenewed.org/

51 Stenberg K, Axelson H, Sheehan P, et al. Advancing social and economic development by investing in women's and children's health: a new global investment framework. Lancet 2014:383:1333-54.

52 http://www.who.int/pmnch/media/press/2013/highlevelpanel_report/en/ 